\title{
Seguimiento de dos pacientes con glomerulonefritis IgA mesangial con antecedentes de exposición a tóxicos (cadmio y disolventes orgánicos)
}

\section{Follow-up of two patients with mesangial IgA glomerulonephritis exposed to cadmium and organic solvents}

\section{J. Fernández ${ }^{1}$ P. Sanz-Gallén ${ }^{2}$, S. Nogué ${ }^{2}$}

\section{RESUMEN}

Realizamos el seguimiento durante varios años de dos pacientes con glomerulonefritis IgA mesangial con antecedentes de exposición a tóxicos (cadmio y disolventes orgánicos).

El primer caso se trata de un varón de 47 años que hace 8 años fue diagnosticado de una glomerulonefritis IgA mesangial; había estado trabajando durante 12 años como soldador. Como metal de aporte para la soldadura utilizaba unas varillas metálicas que contenían un $25 \%$ de cadmio. Se le detectaron concentraciones muy elevadas de cadmio en sangre y orina.

El segundo caso se trata de un varón de 50 años que durante 23 años estuvo expuesto a un amplio número de disolventes orgánicos. Hace tres años se le diagnosticó una glomerulonefritis proliferativa difusa mesangial con depósitos de IgA; a pesar de ello, el paciente continuó trabajando hasta hace un año, en el que se le detectó una enfermedad renal crónica de estadio 3 secundaria a la nefropatía IgA.

Es recomendable que a los pacientes diagnosticados de una glomerulonefritis IgA mesangial se les separe de la exposición a sustancias nefrotóxicas.

Palabras clave. Cadmio. Disolventes orgánicos. Glomerulonefritis IgA mesangial. Toxicología. Medicina del trabajo.

\begin{abstract}
For several years we carried out a follow-up of two patients with IgA mesangial glomerulonephritis with antecedents of exposure to toxic substances (cadmium and organic solvents).

The first case involved a 47 year old male who was diagnosed with mesangial IgA glomerulonephritis eight years ago; he had been working for twelve years as a solderer. He had used metal bars containing $25 \%$ cadmium as part of the soldering material. Very high levels of cadmium were detected in his blood and urine.

The second case involved a 50 year male who was exposed to a wide number of organic dissolvents for 23 years. Three years ago he was diagnosed with a proliferative diffuse mesangial glomerulonephritis with IgA deposits; in spite of that, the patient continued working until one year ago, when was found to have a chronic stage 3 renal disease secondary to IgA nephropathy.

Patients diagnosed with mesangial IgA glomerulonephritis should be kept apart from exposure to nephrotoxic substances.
\end{abstract}

Key words. Cadmium. Organic solvents. toxicology. Mesangial IgA glomerulonephritis. Occupational medicine.
1. Unidad de Toxicología. Laboratorio de análisis Dr. Echevarne. Barcelona.

2. Unidad de Toxicología. Hospital Clínic. Barcelona.

Recepción: 12 de mayo de 2010

Aceptación provisional: 20 de mayo de 2010

Aceptación definitiva: 1 de septiembre de 2010

\section{Correspondencia}

Dr. Pere Sanz-Gallén

Unidad de Toxicología

Hospital Clinic i Provincial

Barcelona

E-mail: 17039psg@comb.es 


\section{INTRODUCCIÓN}

El cadmio es un metal blando, plateado, dúctil y con un punto de fusión de $321^{\circ}$. Su principal vía de absorción en el ámbito laboral es la respiratoria, pudiéndose absorber hasta el $50 \%$ del cadmio inhalado. La vida media biológica oscila entre 10 y 30 años ${ }^{1}$, siendo la vía renal su principal vía de eliminación.

Los disolventes orgánicos son los productos químicos más empleados en el ámbito laboral. Se utilizan como disolventes de pinturas, barnices, tintas, adhesivos y pesticidas. Otros se utilizan para limpiar y desengrasar piezas metálicas y como reactivos o materias primas en la industria química. La exposición se produce habitualmente por inhalación pero la absorción cutánea es a veces importante. Su eliminación es rápida, principalmente por la orina ${ }^{2,3}$.

El cadmio y algunos disolventes orgánicos son potencialmente nefrotóxicos. En este trabajo hemos seguido, durante varios años, a dos pacientes diagnosticados de una nefropatía IgA mesangial, con antecedentes laborales de larga exposición a sustancias nefrotóxicas (cadmio y disolventes orgánicos), con la finalidad de conocer la evolución una vez cesada la exposición a nefrotóxicos laborales, además de incidir en la importancia de identificar los riesgos laborales y realizar una vigilancia de la salud específica según los riegos detectados en cada puesto de trabajo; en estos casos no se realizaron estudios específicos a la exposición al cadmio y a los disolventes orgánicos durante el período que estuvieron expuestos.

La importancia de realizar una historia laboral completa, que pueda ayudar en el diagnóstico de enfermedades profesionales o la detección de enfermedades relacionadas con el trabajo (donde una enfermedad de base se puede agravar con el trabajo, pudiendo ocasionar secuelas irreversibles), también nos ayudará en la detección de trabajadores especialmente sensibles, en los que deberemos aumentar las medidas de protección para minimizar al máximo los riesgos sobre su salud y, en ocasiones, no habrá otra solución que retirarlos de la exposición.

\section{CASOS CLÍNICOS}

\section{Caso 1}

Varón de 47 años, que cesó el hábito tabáquico hace diez años, fumó entre 10-20 cigarrillos/ día durante 15 años y fue diagnosticado hace 8 años de glomerulonefritis mesangial IgA. Había estado trabajando durante 12 años como soldador en una empresa de fabricación de discos de acero que llevaban insertados unos "dientes" de cobalto y carburo de tungsteno que se utilizan para cortar mármol y granito. El soldador utilizaba un sistema de soldadura autógena de la que utilizaban, como metal de aporte, unas varillas metálicas a base de: plata (39\%), cadmio (25\%), cobre (22\%) y zinc (14\%). Consumía $1 \mathrm{Kg} / \mathrm{sema}-$ na; no utilizaba equipos de protección respiratoria y su lugar de trabajo no tenía un sistema de extracción localizada de humos. Las concentraciones de cadmio en su puesto de trabajo fueron de $52 \mu \mathrm{g} / \mathrm{m} 3$ (Valor Límite Ambiental (VLA) es de $10 \mu \mathrm{g} / \mathrm{m} 3$ ). Durante los doce años que estuvo trabajando se le había realizado un reconocimiento inicial y dos reconocimientos periódicos inespecíficos sin controlar la exposición al cadmio y a otros contaminantes químicos; los resultados del laboratorio se encontraban dentro de la normalidad (hemograma completo, glucemia, colesterol, transaminasas hepáticas, creatinina sérica y el estudio cito-químico de orina). En una analítica general realizada por su médico de familia se le detecta una microhematuria y una proteinuria. Cuando su médico le realiza la historia clínica detecta la exposición a humos de cadmio por lo que es remitido a la Unidad de Toxicología de nuestro hospital. Al ingreso el paciente está asintomático, no tiene antecedentes personales ni familiares nefrológicos, no tiene problemas de obesidad, ni de diabetes (las glucemias son normales), no toma ningún tipo de medicación de forma habitual y la presión arterial es de 105/65 mm/Hg. En la analítica destaca una proteinuria de $2 \mathrm{~g} / 24 \mathrm{~h}$, microhematuria de 150 hematíes/campo, cadmio en sangre de $20 \mu \mathrm{g} / \mathrm{l}$ (Valor Límite Biológico [VLB]: $5 \mu \mathrm{g} / \mathrm{l}$ ) y cadmio en la orina de $85 \mu \mathrm{g} / \mathrm{g}$ de creatinina (VLB: $5 \mu \mathrm{g} / \mathrm{g}$ creatinina). Debido a que las afectaciones renales eran de tipo glomerular, y el cadmio ocasiona principalmente lesiones de tipo tubular, se le recomendó un estudio mediante una biopsia renal. En la microscopía óptica se observaron cinco glomérulos, uno de ellos totalmente esclerosado; el resto mostró una ligera hipercelularidad segmentaria; en dos glomérulos se detecta una proliferación segmentaria extracapilar y focos de fibrosis intersticial con atrofia tubular. La inmunofluorescencia fue positiva para C3 (+++) y IgA (++) con patrón mesangial. El diagnóstico fue de una glomerulonefritis focal Ig 
A mesangial y se inició tratamiento con enalapril $10 \mathrm{mg} /$ día. Debido a las altas concentraciones de cadmio en líquidos biológicos (sangre y orina), que después de ocho años de hacer cesado la exposición se encuentran por encima de los valores límites máximos permitidos en España en trabajadores expuestos al cadmio, el paciente fue apartado de su trabajo; además, se le consideró un trabajador especialmente sensible a la exposición a nefrotóxicos donde aconsejamos que se evitase su exposición con la finalidad de minimi- zar al máximo la posibilidad de que el paciente evolucione hacía una enfermedad renal crónica. Se le realizó un seguimiento durante 8 años (los valores de creatinina sérica, filtrado glomerular, proteinuria y sedimento urinario vienen expresados en la tabla 1) y los repetidos controles de beta2-globulina y de $\mathrm{N}$-acetilglucosaminidasa (NAG) se encontraron dentro de la normalidad. En el momento actual las concentraciones de cadmio en sangre son de $7 \mu \mathrm{g} / \mathrm{l}$ (VLB: $5 \mu \mathrm{g} / \mathrm{l})$ y el cadmio en orina es de $18 \mu \mathrm{g} / \mathrm{g}$ (VLB: $5 \mu \mathrm{g} / \mathrm{g}$ ).

Tabla 1. Evolución de la creatinina sérica, proteinuria, aclaración de la creatinina y sedimento urinario desde el diagnóstico hasta la actualidad.

\begin{tabular}{|l|c|c|c|c|}
\hline $\begin{array}{c}\text { Años } \\
\text { (después de la } \\
\text { exposición) }\end{array}$ & $\begin{array}{c}\text { Creatinina } \\
\text { (mg/dI) }\end{array}$ & $\begin{array}{c}\text { Proteinuria } \\
\text { (g/24 horas) }\end{array}$ & $\begin{array}{c}\text { Aclaración de } \\
\text { creatinina } \\
\text { (ml/min) }\end{array}$ & $\begin{array}{c}\text { Hematuria } \\
\text { (hematíes/campo) }\end{array}$ \\
\hline Inicial & 1 & 2 & 150 & 150 \\
\hline 1 año & 1,1 & 1,7 & 91 & $50-100$ \\
\hline 2 años & 1 & 1 & 121 & $21-50$ \\
\hline 3 años & 1,2 & 1,2 & 132 & $11-20$ \\
\hline 4 años & 1,2 & 1,4 & 135 & $4-10$ \\
\hline 5 años & 1,3 & 1,2 & 70 & $4-10$ \\
\hline 6 años & 1,06 & 0,95 & - & $1-3$ \\
\hline 7 años & 1,01 & 0,62 & - & $1-3$ \\
\hline 8 años & 1,03 & 0,28 & & 40 \\
\hline
\end{tabular}

\section{CASO 2}

Varón de 50 años, no fumador. Como antecedentes personales destaca dos ingresos hospitalarios por intoxicación aguda por organofosforados. Aporta 10 informes de reconocimientos médicos periódicos realizados durante los 23 años que ha trabajado en una empresa que fabricaba diversos productos fitosanitarios y para su obtención empleaba un amplio número de disolventes orgánicos, entre ellos acetona, acetofenona, ciclohexanona, nafta, tolueno y xileno, donde el único control específico realizado esporádicamente es a la exposición a organofosforados (determinación de la acetilcolinesterasa intraeritrocitaria), no presenta antecedentes personales ni familiares de nefropatías, las analíticas generales de sangre y orina son normales, las tensiones arteriales oscilan entre $100 / 60 \mathrm{~mm} / \mathrm{Hg}$ a $120 / 80 \mathrm{~mm} /$ Hg. En uno de los reconocimientos realizados hace 5 años se le detectó proteinuria y microhematuria, creatinina sérica 1,06 mg/dl; en el nuevo reconocimiento realizado el año siguiente pre- senta una creatinina de $1,43 \mathrm{mg} / \mathrm{dl}$, hematuria (10 hematíes/campo), proteinuria $1 \mathrm{~g} /$ día. Hace tres años fue diagnosticado de una glomerulonefritis proliferativa mesangial difusa con depósitos de IgA. En el estudio de la biopsia renal destacaba un $20 \%$ de glomérulos con esclerosis severa, un $10 \%$ estaban obliterados, había una fibrosis intersticial, atrofia tubular, discreto infiltrado inflamatorio crónico y en la inmunofluorescencia se detectaban depósitos mesangiales difusos de IgA y C3; a pesar de ello, siguió trabajando hasta hace un año, que fue diagnosticado de una enfermedad renal crónica de grado 3 .

La evolución de las analíticas renales, realizadas cada seis meses desde que se realizó el diagnóstico hasta la actualidad, vienen expresadas en la tabla 2. Las determinaciones puntuales de beta 2-microglobulina y NAG urinarios se encontraban dentro de los valores de normalidad. Después de un año de haber cesado su actividad laboral la proteinuria y la hematuria se normalizaron pero la creatinina sérica se mantuvo alta. 
Tabla 2. Evolución semestral de la creatinina sérica, proteinuria, aclaración de la creatinina y sedimento urinario desde el diagnóstico hasta la actualidad.

\begin{tabular}{|c|c|c|c|c|}
\hline $\begin{array}{c}\text { Meses } \\
\text { (después del } \\
\text { diagnóstico) }\end{array}$ & $\begin{array}{c}\text { Creatinina } \\
\text { (mg/dl) }\end{array}$ & $\begin{array}{l}\text { Proteinuria } \\
\text { (g/24 horas) }\end{array}$ & $\begin{array}{c}\text { Aclaración de } \\
\text { creatinina } \\
\text { (ml/min) }\end{array}$ & $\begin{array}{c}\text { Hematuria } \\
\text { (hematíes/ } \\
\text { campo) }\end{array}$ \\
\hline $\begin{array}{l}\text { Inicial } \\
\text { (diagnóstico) }\end{array}$ & 1,56 & 3,18 & 110 & 10 \\
\hline A los 6 meses & 1,56 & 2,16 & 84 & 10 \\
\hline A los 12 meses & 1,57 & 2,15 & 76 & 10 \\
\hline $\begin{array}{l}\text { A los } 18 \text { meses } \\
\text { (inicia baja médica) }\end{array}$ & 1,70 & $\begin{array}{c}1,3 \\
\text { (1,2 albúmina/24 horas) }\end{array}$ & 68 & 20 \\
\hline $\begin{array}{l}\text { A los } 24 \text { meses } \\
\text { ( } 6 \text { baja médica) }\end{array}$ & 1,60 & $\begin{array}{c}0,65 \\
(0,6 \text { albúmina/24 horas) }\end{array}$ & - & 5 \\
\hline $\begin{array}{l}\text { A los } 30 \text { meses } \\
\text { (12 meses de baja) }\end{array}$ & 1,70 & negativo & - & negativo \\
\hline $\begin{array}{l}\text { A los } 36 \text { meses } \\
\text { (18 de baja médica) }\end{array}$ & 1,70 & negativo & - & negativo \\
\hline
\end{tabular}

\section{DISCUSIÓN}

Los órganos diana después de la exposición al cadmio son los pulmones, riñones, huesos y sistema hematopoyético ${ }^{4}$. Si bien el túbulo proximal es el principal afectado en la nefropatía inducida por cadmio, los glomérulos renales también están expuestos a metales circulantes durante la filtración plasmática y también pueden resultar alterados por el cadmio $^{5,6}$. Varios estudios indican una mayor incidencia de alteraciones renales en los trabajadores que presentan concentraciones de cadmio en orina por encima de los $10 \mu \mathrm{g} / \mathrm{g}$ de creatinina ${ }^{7,8}$.

En el primer caso que se presenta, a pesar de que la nefropatía es básicamente glomerular y no es tan específica a la exposición al cadmio, la mejoría del paciente ha sido evidente tanto por el descenso de la proteinuria como de la microhematuria. La administración de IECA ha podido contribuir a que la nefropatía no progrese hacia una enfermedad renal crónica, pero seguramente el factor más importante es el cese en el trabajo, destacando la retirada de la exposición al cadmio (un importante nefrotóxico).
La exposición laboral a disolventes orgánicos se les ha asociado con necrosis tubular aguda, alteraciones intersticiales y glomerulopatías ${ }^{2,9}$. Diversas publicaciones describen pacientes que presentan una glomerulonefritis inicial y que si están expuestos a disolventes orgánicos puede aumentar de forma significativa el riesgo de que se desencadene una enfermedad renal crónica ${ }^{10}$. En otro estudio de Jacob $\mathrm{y} \mathrm{col}^{3}$ han investigado a 269 pacientes con diferentes tipos de glomerulonefritis (entre ellas la nefropatia IgA) y encuentran que los expuestos a disolventes del grupo de las cetonas tienen 13 veces más riesgo de que la glomerulonefritis inicial degenere en una enfermedad renal crónica. Los derivados del petróleo presentan un riesgo de 8,7 veces más y los expuestos a tolueno o al xileno presentan 5 veces más riesgo de presentar una enfermedad renal crónica.

En el segundo caso, desde que se detectaron alteraciones de la analítica renal, se tenía que haber investigado la posible exposición a sustancias nefrotóxicas con la finalidad de minimizar al máximo el 
riesgo de ocasionar una enfermedad renal crónica, a pesar de ello el trabajador siguió estando expuestos a disolventes orgánicos.

Podemos concluir que hay que intentar retirar de la exposición a cadmio y disolventes orgánicos a aquellos trabajadores que se consideren especialmente sensibles con la finalidad de evitar una afectación irreversible.

\section{BIBLIOGRAFÍA}

1. JÄrup I, Rogenfelt A, Elinder CG, Nogawa K, KJELLSTRÖM T. Biological half-time of cadmium in the blood of workers after cessation of exposure. Scand J Work Environ Health 1983; 9: 327-331.

2. BRAutbar N. Industrial solvents and kidney disease. Int J Occup Environ Health 2004; 10 : 79-83.

3. Jacob S, Héry M, Protois JC, Rossert J, Stengel B. New insight into solvent-related end-stage renal disease: occupations, products and types of solvents at risk. Occup Environ Med 2007; 64: 843-848.
4. Fernández MA, Sanz P, Palomar M, Serra J, GaDEA E. Fatal chemical pneumonitis due to cadmium fumes. Occup Med (Oxford) 1996; 46: 372-374.

5. Nogué S, Sanz-Gallén P, Torras A, Boluda F. Chronic overexposure to cadmium fumes associated with IgA mesangial glomerulonephritis. Occup Med (Oxford) 2004; 54: 265-267.

6. XiaO W, LIU Y, Templeton DM. Pleiotropic effects of cadmium in mesangial cells. Toxicol Appl Pharmacol 2009; 238: 315-326.

7. JÄRuP L, ELINDER CG, SANG G. Cumulative bloodcadmium and tubular proteinuria: a doseresponse relationship. Int Arch Occup Environ Health 1988; 60: 223-229.

8. Bernard AM, Roels H, Cardenas A, Lauwerys R: Assessment of urinary protein 1 and transferrin as early markers of cadmium nephrotoxicity. Br J Ind Med 1990; 47: 559-565.

9. Porro A, Lomonte C, Coratelli P, Passavanti G, Ferri GM, Assennato G. Chronic glomerulonephritis and exposure to solvents: a casereferent study. Br J Ind Med 1992; 49: 738-742.

10. Jacob S, Héry M, Protols JC, Rossert J, StenGEL B. Effect of organic solvent exposure on chronic kidney disease progression: the GNPROGRESS cohort study. J Am Soc Nephrol 2007; 18: 274-281. 
